\title{
Implementation of Pedagogical Blogs in the Process of Formation Information-Based Educational Environment
}

\author{
Maksimova Natalya Aleksandrovna \\ Andreeva Anna Victorovna \\ Smolensk State University, Russia, Smolens, Federal State Educational Institution of Higher Professional Education «Smolensk \\ State Academy (University College) of Physical Education, Sport and Outdoor Recreation», Russia, Smolensk
}

\author{
Doi:10.5901/mjss.2015.v6n6s1p129
}

\section{Abstract}

The paper highlights the modern perception of such a concept as information-based educational space and draws the latest statistics on the implementation of information technologies in the process of education in Russian Federation. It also examines the main concepts, which make up the framework of building up a unified integrated information-based educational environment. Current tendencies in the development of the modern society as well as its clearly marked informatization account for an arising need for a more extensive implementation of information technologies in the field of education, in particular the use of pedagogical blogs. These days any educated person regardless of their professional occupation needs to have sufficient skills of working with various electronic means to process and transfer information. In the circumstances when there is an evident need for a more active and extensive implementation of innovative educational technologies, the system of basic and professional education itself acts as an accelerator of the informatization process in the modern society. It also serves as a tool of forming informational culture of any person and any educating specialist of the new formation, able to apply in their professional work modern information technology and network resources in the form of teaching blogs.

Keywords: information-based educational space, pedagogical blog, electronic textbook, system of education, teaching process.

\section{Introduction}

Federal programmes aimed at fostering the development of education in the Russian Federation in the first decade of the $\mathrm{XXI}$ century gave a significant impulse to the spreading of information and communication technologies as well as to the growth of information environment in the field of education. Furthermore, they created certain elements of the Russian overall unified information-based educational environment. It, in turn, contributed to upgrading Russia's international rating. Thus, in the international rating on the information and communication technologies development Russia rocketed from the 70th place (2007) to the $38^{\text {th }}$ place (2012); moreover, in the rating on the Internet development among all the world countries it took the $31^{\text {st }}$ place (2013), and as for the level of the intensity of the Internet implementation, it got the $24^{\text {th }}$ place.

Ensuring modernization of the educational process resulted in an increase in the amount of spending on the system of education. Nowadays according to the data generated in the process of monitoring carried out by various companiesthere are on average the following characteristics of the educational system in Russia:

- index "Share of those institutions which have at least one multimedia projector (of the total number of educational institutions)" amounts to $91,76 \%$,

- index "Share of those schoolchildren and students who study at an educational institution which has at least one multimedia projector (of the total number of schoolchildren and students)" is $98,3 \%$,

- index "Share of those institutions where there is at least one interactive whiteboard (of the total number of educational institutions)" has recently risen to $74,70 \%$,

- index "Share of those schoolchildren and students who study at an educational institution which has at least one interactive whiteboard (of the total number os schoolchildren and students)" throughout the Russian Federation is $90,34 \%$.

On average, access to the Internet with the speed which is not lower than $129 \mathrm{Kbps}$ is available at $69 \%$ educational institutions and, correspondingly, for $59,35 \%$ of schoolchildren and students in Russia [Maximova N.A., 2012].

Access to the Internet with the speed which is not lower than $2 \mathrm{Mbps}$ is provided on average in $25,86 \%$ educational 
institutions for $38,98 \%$ schoolchildren and students.

More than $40 \%$ of educational institutions have access to the Internet with the speed not less than 2 Mbps in the Nizhny Novgorod region, the Republic of Tatarstan, the Kaliningrad region, the Leningrad region, the Murmansk region, in St. Petersburg, in Moscow, in the Sverdlovsk region, the Chelyabinsk region, the Yaroslavl region, the Astrakhan region (44 598 educational institutions took part in the monitoring process).

The total number of computer laboratories in Russian educational institutions amounts to 63120 . Correspondingly, the total number of computers is 1406656 units. According to the latest statistics, each educational institution in Russia has, on average, 1,4 computer laboratory which means that there is one computer for 9,5 schoolchildren and students [Maximova N.A., 2012, 2013].

The abovementioned characteristics of the development of the information and communication technologies infrastructure in educational institutions have almost come up with the average European ones. This being said, schools and the authorities in the educational institutions will definitely have to deal with issues of providing proper support to scaffold the development of the information and communication technologies infrastructure in order to achieve current educational goals [Maximova N.A., 2009].

\section{Discussions}

In the recent years the main trends of the implementation of information and telecommunication technologies in education have already been formed. Among these technologies, there are the following ones: implementation of automated systems and complexes to manage the process of education; adaptation of information technologies as didactic means; increase in the creative component of the overall study and research activities.

Currently there are the following main goals in the informatization process of education [Bocharov, A.A. 2013]:

- $\quad$ upgrading the quality of the teaching process for future specialists on the basis of implementation of cuttingedge information technologies in education;

- introduction of active teaching methods and, thus, increasing the creative and intellectual component of the educational activity;

- adaptation of various information technologies in order to meet individual needs of every student;

- working out and designing information technologies for the system of distance learning;

- improving the methodical guidelines to perfect the process of education.

In recent years there has been worked out and introduced a concept of development of a unified integrated information-based educational environment. Certain provisions about building up such an environment have already been included in the new federal law "On education". This document aims at ensuring access to a high-quality education for all schoolchildren and students regardless of their place of living, social and material status of themselves and their families. It also strives to provide equal availability of all educational programmes at all stages of the educational process to all children [Bocharov, A.A. 2013]. This federal law defines and determines the main goals, practical objectives, the main guidelines for functions, structure and potential results of the development of this unified integrated information-based educational environment.

New forms of work in this field imply the modification and reduction of personal contacts between the teacher and the student, which results in heightened need for creating high-quality electronic educational resources as well as methods and technologies of their implementation.

While working out designs there spring up problems in creating virtual educational cyberspace at the new informational level. Ensuring unity of the information-based environment turns out to become the main problem at this level. There are also difficulties in involving teachers in the process of creating such an environment. The experience of practical work helps to distinguish what conditions are needed to create teachers' own information resources. The majority of educators are very conservative. Consequently, this quality determines the existence of certain difficulties in introduction of innovative methods and technologies, which are dramatically different from the traditional ones. In the process of forming teachers' readiness for the use of information and communication technologies, we can identify an even greater hindrance than teachers' conservative attitude, namely, the passive and inert character of the structure of all educational institutions. To prove the credibility of this statement we can refer to certain defects in the activity performed by the school authorities which result in lack of teachers' spare time which they may spend on informatization of the teaching process. Such defects also cause insufficient teaching staff as well as deficit of support and motivation for teachers' innovative activity.

There are also such cases when quite highly qualified specialists who are in charge of managing the process of education do not fully realize the importance and need for introduction of information and communication technologies, 
for working out the corresponding policy and for setting specific standards concerning their implementation. Consequently, these authorities maintain a negative attitude of non-involvement. Nowadays we can identify the task to fill the educational environment with proper informational resources as the most significant and challenging one.

Design of a high-quality electronic educational resource is a complicated process of integrating the description of a certain subject area with specific didactic means and modern information technologies [Andreeva A.V., Maksimova N.A. 2013]. All the three abovementioned integral parts are closely intertwined and interrelated. Enhanced characteristics of a modern computer presentation provide teachers with golden opportunities to use diverse didactic means in order to upgrade the quality of the educational process. Unfortunately, the majority of teachers are not ready to embrace these opportunities.

One of such means of interaction between teachers and students is blogging. Blogs are essentially web logs. Web logs or blogs became famous worldwide on the Internet thanks to an American project LiveJournal.com which was launched in the 90s. In the Russian part of the Internet there was a word-for-word translation, namely, "Live Journal" which is abbreviated as "LJ", and became the most famous blog-service in the first decade of the XXI century. The author of such a live journal can make short notes which are presented then in a certain chronological order. Unlike personal diaries, which authors hold primarily for themselves, web logs are aimed at drawing attention of as many people as possible. It is not for nothing that the most popular web logs, whose target audience amounts to several thousand readers, are regarded as the mass media. By publishing various notes and creative essays online, the authors hope to get an active feedback from their readers. Sometimes they even consciously provoke their readers to give a certain feedback. In this case a blog may successfully turn into a popular platform for discussion or an environment for communication.

Another platform for creating blogs is a service the popularity of which is constantly growing - Blogger (http://blogger.com). One can create a blog and place any text, graphic and practically any multimedia information there. Such blogs can incorporate links to valuable Internet resources as well as various external application, such as flash clips, news feeds, simulation training systems, tests, gadgets etc. Blogger is a very convenient universal tool which provides all necessary services to make a blog highly appealing for all categories of users, i. e. for kids, teenagers and adult readers. Some serious content can be efficiently combined with teaching or entertaining material. Games can also be integrated in it.

Nowadays there are more than 30 million blogs on the Internet. Moreover, their number is increasing every second. Bearing in mind that the main purpose of any blog is to transfer certain information from the writer to the reader, we can identify the most significant factors which result in such a dramatic rise in popularity of blogs worldwide. Firstly, it is the simplicity of blog creation and publishing information there. Secondly, it is easiness of arranging, providing and ensuring interaction between authors and readers, which can, in turn, lead to the formation of Internet communities. Thirdly, it is quickly growing availability of the Internet and high speed of information spread.

In the educational context, teachers can create professional blogs which are directly related to a certain subject, namely, to a class, section, teaching methodology, class supervision, to exam preparation, to interaction with parents or colleagues etc.

Contemporary typology of educational websites can be presented in the following way [Maximova N.A. 2009].

Blog of a single class or on a single topic. It can contain both some basic materials and some additional text, audio- or visual Internet materials which are specifically selected by the teacher.

Blog of a subject-teacher. It comprises a collection of teaching materials, the so-called thematic collection. Throughout their professional careers teachers create a great number of materials and creative tasks worked out and designed themselves, namely, presentations, task and test materials, handouts, best practices, methodological recommendations for students and colleagues. With the help of the blog, teachers obtain an excellent opportunity to sort out all the teaching material, utilize the beneficial educational resources on the blog and, thus, make up a desired educational content. The technology of blog creation provides users with an opportunity to upload a wide range of authors' own materials which may include diverse audio- and video materials, references to interesting educational sites, text materials, laboratory tasks, preparation material for the Unified State Exam in different subjects which is called EGE in Russia etc.

Blog of the class or the class supervisor. It can function as an "information panel" both for students and for their parents. Such blogs can contain photo albums of various class events, discussion boards on a wide range of topics, teaching plans, useful references, announcements etc.

Blog as an educational project. It can be beneficial for students who carry out some research or project work. Firstly, project guidelines including detailed instructions and description of the working procedure can be placed there. The guidelines can also comprise links to useful applications and educational resources which can scaffold the project 
work. Secondly, blog can serve as a place for publishing students' reports on the project outcomes. Furthermore, on the basis of the participants' comments there can be launched a discussion on the blog.

Student's blog or an electronic notebook. This is a student's electronic space where he can place their own materials such as presentations, drawings, creative homework etc. This kind of blog is made up by the student and can be demonstrated to the teacher for further assessment.

A student gets an excellent opportunity to perform the following activities:

- publish their own work online;

- submit a report on the outcomes of a certain research in any kind of a wide range of various possible formats;

- express their creative potential through publishing the results of their creative activity or merely of a hobby;

- $\quad$ not to use any additional electronic devices;

- have access to all their materials outside of school at any time.

Such blog can serve as the student's electronic portfolio which will comprise not only the homework materials, but also all the information about the student's accomplishments and interests as well as electronic tools for online communication with friends.

\section{Conclusions}

Blog provides an opportunity to expand the student's educational space. The school has already stopped being an only source of educational information. Nowadays the overall educational environment is changing. Recently there have been springing up new "environments" which will enable students to acquire social skills and skills of cooperation and teamwork.

Blog is an efficient tool for distance support of students. This kind of blogs is made up specifically for those students who are either temporarily absent from classes or who practice homeschooling. The peculiarity of such blogs is that they comprise materials on several subjects submitted by different teachers. It can represent some basic teaching materials for self study or materials of a higher level of difficulty or aimed at expanding the student's horizon. Interactive tests and questionnaires created with the help of Google services allow to register the students' results automatically and also allow to conduct distant tests.

Pedagogical blog is a new educational reality. In our opinion, the most significant characteristic of a blog activity is that a blog can and should become a means of self-expression and one of the efficient means to realize one's own professional competence. When educators start creating their own blogosphere they will start modeling their own alternative educational space.

\section{References}

Andreeva A.V., Maksimova N.A. (2013). ISU higher education institution as an instrument of quality management of education. In the World of Scientific Discoveries, 11.8, 22-28.

Andreeva A.V., Maximova N.A., Lifanov A.A. (2013). Development of the market of Internet providers in the Smolensk region. Regional research, 4, 44-48.

Andreeva A.V., Mazhar E.N., Maximova N.A. (2014). Some Aspects of Implementation of Information Technologies in the Teaching Process. Middle-East Journal of Scientific Research, 19 (1), 19-23.

Bocharov, A.A. (2013). Staff Training in Ltd «Crystal». Nonferrous metals, 2, 36-37.

Framework of the development of the unified information-based educational environment in the Russian Federation [2014]. - Available: http://minobr.gov-murman.ru/opencms/export/sites/minobr/.content/docs/GLAS/koncepciya_eios.pdf (February 24, 2014).

Framework of the Republican scientific conference "Informational educational environment of the XXI century as a prerequisite of development of the teacher's professional competences: background, problems and prospects" [2014]. - Available: http://www.pandia.ru/text/77/195/40596.php (February 24, 2014).

Maximova N.A. (2008). Electronic educational means. Academic proceedings of the Institute of the Society Informatization at the Russian Academy of Education, 27, 251-252.

Maximova N.A. (2009). Methodical peculiarities of studying the course "Audio-visual technologies in teaching computer science". Informatics and education, 3, 97-99.

Maximova N.A., (2012), Problems of forming informational educational environment of an educational institution, Informatics and education, 8, 90-91.

Maximova N.A. (2012). Technological culture of a teacher: principles of its formation with the implementation of innovative technologies. Saarbrücken: LAP LAMBERT Academic Publishing GmbH \& Co. KG.

Maximova N.A. (2013). System of forming the teacher's technological culture. Modern problems of science and education, 1. URL: www.science-education.ru/107-8569 (date of reference: 24.02.2014). 